\title{
Accountants' Perceptions Of Internal Control Problems Associated With The Use Of Computerized Accounting Systems: Evidence From Bahrain
}

Sayel Ramadhan, Ph.D. (Email: sayel@buss.uob.bh), University of Bahrain

Prem Lal Joshi, Ph.D. (Email: joshi@buss.uob.bh), University of Bahrain

Salwa Abdel Hameed, Ph.D. (Email: salwa@buss.uob.bh), University of Bahrain

\begin{abstract}
The objective of this study is to investigate Bahraini accountants' perceptions of internal control problems associated with their use of computerised accounting systems and how such problems may be resolved. A three-section questionnaire was developed to collect the data. A sample of (100) firms was selected for the study. Sixty-two questionnaires were returned duly completed (a response rate of $62 \%)$. Descriptive statistics and ANOVA were used to analyse the data. The results indicate that Bahraini accountants perceive that there exist some internal control problems associated with the use of computer-based accounting systems. The most important problem is that information can be changed without physical traces. However, they perceive that certain control procedures can be undertaken to overcome them (e.g., ensure that only authorised people have access to computers and records; use of backup copies; effective testing of programs for problems noted and separation of duties within data processing). Significant differences were found in some of the problems faced by the firms according to the nature of business operations.
\end{abstract}

\section{Introduction}

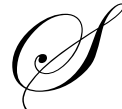

ince computers became available in the 1950s, they have spread throughout the business world. From the beginning, accounting and bookkeeping have been the popular applications for computer technology. Consequently, many organizations switched over from manual accounting systems to computer-based accounting systems. Computers are widely used in accounting because they are able to efficiently store, process and summarize large quantities of financial data. Furthermore, computers perform these functions very rapidly and with greater accuracy than can be achieved in a manual accounting system (Larson and Miller, 1997).

In addition to the above advantages, a computer-based accounting system eliminates some of the major internal control concerns associated with manual accounting systems. Page and Hooper (1992) state that the computer is more accurate than any person performing the same calculations. Unlike the human clerk, the computer will not issue invoices incorrectly or accept a journal entry that does not balance or post an entry to the wrong account. The computer will be consistent in its treatment of transactions (Page and Hooper, 1992). For example, if the program instructs the computer to check the customer's credit limit before the sale, the computer will always consistently check the credit limit. The computer will not have any dishonest or disloyal motivations, since the machine cannot profit from any misstatement. In a manual system, the employee may take actions that help him achieve his own goals before those of the company.

Larson and Miller (1997) claim that computers allow more extensive testing of records for audit purposes (i.e., application controls embedded in software). The regular review and audit of computerised records can include

Readers with comments or questions are encouraged to contact the authors via email. 
more extensive testing because more information can be accessed rapidly. When a manual system is used, managers may select only small samples of data to test in order to reduce costs, because testing is expensive.

The advantages of computerized accounting systems are appreciated by both accountants and managers in an organization. With the aid of computer technology, accountants can now produce financial statements and other special reports on demand. This assists management decision making in such a way that managers can now rely on the information produced by the accounting system with more confidence, and they can respond more rapidly to changes in the business environment as a result of more timely reports (Hearing, 1994).

Despite the above advantages and the fact that some of the internal control concerns associated with manual accounting systems can be eliminated with the use of computers, managers are faced with the problem of a more complex accounting information system (Pesqueux, 1993). They are faced with the internal control problems associated with computer-based accounting systems. Nevertheless, there are internal control procedures which assist in overcoming such problems.

The main purpose of this study is to examine the extent to which internal control problems associated with the use of computerized accounting systems exist and how such problems may be resolved.

\subsection{Importance of the Study}

The study is considered important due to the following reasons. First, a focus on the internal control problems of computer-based accounting system is crucial because of the enormous importance of computer systems to business. Page and Hooper (1992, p. 117) showed the reliance of most businesses surveyed on their computer system. The survey showed that $19.6 \%$ were "totally dependent" and $65.8 \%$ were "heavily dependent" and $13.9 \%$ were "moderately dependent". The remaining $0.7 \%$ were "slightly dependent". Moreover, seventy-five percent of the respondents stated that they would have a critical or total loss of functioning within fourteen days if they lost their computer support. Second, the results of the study should help firms overcome the internal control problems that are likely to arise in computerized accounting systems.

\section{Theoretical Background}

\subsection{Internal Control}

The Statement on Auditing Standards No. 1 (AICPA, 1972) provides the following definition for internal control: "Internal control comprises the plan of organisation and all the coordinated methods and measures adopted within a business to safeguard its assets, check the accuracy and reliability of its accounting data, promote operational efficiency and encourage adherence to prescribed managerial policies". However, Leitch and Davis (1992) point out that the above definition of internal control recognizes a broad responsibility on the part of accountants for the organisation's control structure. On the other hand, the Committee of Sponsoring Organisations of the Treadway Commission (1992), popularly known as COSO report, defines internal control "as the process implemented by the board of directors, management, and those under their direction to provide reasonable assurance that control objectives are achieved with regard to effectiveness and efficiency of operations, reliability of financial reporting, and compliance with applicable laws and regulations". COSO represents a significant move away from an internal control definition that is confined to accounting controls to one that addresses a wide range of board and management objectives. This report emphasized that an internal control should consist of five interrelated components: (1) control environment, (2) risk assessment, (3) control activities, (4) information and communication, and (5) monitoring.

Holm and Laursen (2002) examined the perceptions of internal control at different points in time. The content analysis provide a detailed description of the development in the conceptual understanding of internal controls and contrasts the perceptions as experienced by external auditors, internal auditors, management and shareholders. Specific internal control procedures vary from company to company and depend on such factors as the nature of the business and its size. However, the same broad principles of internal control apply to all companies. These broad principles are (see Arens and Loebecke, 1997): 
1. Clearly established responsibilities.

2. Maintain adequate records.

3. Insure assets and bond employees.

4. Separation of duties.

5. Divide responsibilities for related transactions.

6. Use mechanical devices whenever practicable.

7. Perform regular and independent reviews.

\subsection{Internal control problems}

As firms have become increasingly dependent upon the computerised accounting information systems, these systems have also become more complex in return to meet the information needs of these firms. Due to increasing complexity and importance, companies are facing internal control problems associated with the use of computers. As a result, ensuring that the accounting information system is sufficiently controlled, has become an extremely important issue. The following four main internal control problems are examined (i.e., input, processing, storage and output).

\subsubsection{Problems at Input Stage}

Invisibility of input data

Quite often entries, not based on source documents, are directly entered into the computer. For example, a terminal operator can make an entry directly into the computer based on telephone messages. The clerk at the reservation desk in an airline company receives a phone call without a source document. Even if there are source documents, retrieval is often difficult, or because of retention policy, they exist for only a short time (Arens and Leobbecke, 1997). In such cases, the data put into the system is invisible. It is in machine readable form only.

The solution to overcome this problem is to have physical control over the terminals by way of a lockable keyboard and insure that only authorised persons initiate transactions. In addition, each transaction should be tied back to the operator, terminal, and time when it was initiated.

Unauthorized access

Computerised accounting systems allow easy access to data and use of the data for legitimate purposes. However, these facilities may also allow easy access for illegitimate purposes. For example, unauthorised transactions may be initiated through the computer. A standard solution to data processing is to have various physical, organizational, and other internal controls on the entry of data to the computer system. In addition, the system should allow the check of all authorisations through programmed controls.

Unfamiliar user may input incorrect data

A user of a program is generally not intimately familiar with it and will often put in erroneous data or may respond incorrectly. Wilkinson and Cerullo (1997, p.308) state that the logical capabilities of computer systems enable a wide variety of input errors to be detected. Each computer-based transactions processing system can and should incorporate logical data error-detecting edit tests. The editing procedure has the purpose of screening and comparing all incoming data against established standards of validity.

\subsubsection{Processing Stage Problems}

The computer equipment lacks judgement

In a manual system, people can use their judgement and can realize that something is wrong. On the other hand, computers as machines have no judgement of their own and sometimes may do strange things if told to do them. The solution to this problem is to have judgement built into the computer system through programmed controls. 
Centralisation of data and separation of duties

Accounting textbooks (e.g. Page and Hooper, 1992 and Hall, 1995) and previous research suggest that the separation of duties is one of the basic elements of effective internal control. For example, in a manual system, the duty of journalizing transactions is separated from the duty of posting transactions to the ledger accounts. However, in a computer-based system, these duties and many others are concentrated within the system. If a person has unauthorized control of the computer, the internal control element "separation of duties" will not be effective. The solution to this problem is the separation of knowledge and access. Those with knowledge of how the system works (such as programmers) should not have access to the computer.

Great speed of computers can be misused

One of the protections in manual systems is the human limitation of speed in altering checks and other records. Since the computer has the ability to process with greater speed, records can be changed in a limited time. Two possible solutions are available to overcome this:

- $\quad$ The system must provide for a review of all programs by a supervisor.

- $\quad$ Physical protection of programs from unauthorised modification.

Some Potentials for Error

Manual systems are susceptible to numerous types of errors, such as incorrect calculations and postings. In computer-based systems, the potential for error is generally reduced; however, new and difficult sources of errors can be created (e.g., vendor-supplied errors). These errors include faulty hardware or errors in the system software, such as operating systems and can be detected quickly. However, rare errors may occur in the application programs. A poor design of either the program or the system can create errors. The solution is proper system design. The system should be designed to handle unusual situations and circumstances.

\subsubsection{Storage Stage Problems}

Invisibility of audit trail

Audit trail is the accumulation of source documents and records that allow the organisation to trace accounting entries back to their initiation and the reverse (Arens and Loebbecke, 1997). With the use of audit trail, one can trace transactions forward from detail (source documents) to summary (financial statements) and backward from summary to detail. Even though it is not possible to see the audit trail, it does exist, but only in a machine-readable form. This invisibility of records and the analysis of support for figures on financial statements are made more difficult. The checking and analysis cannot be done manually (Page and Hooper, 1992). The computer must be used to analyse its own records and audit trail. Therefore, the system has to be designed to incorporate the data for all necessary analysis.

Information can be changed without physical traces

In a manual system, any distortion of records can be easily traced as the records are in ink. It becomes visible if the records are erased. But in a computer-based system, this is not possible because information can be changed without a trace. Consequently, there is no similar protection for accounting records in a computerised system.

Protection against this problem is difficult, but it can be concentrated in two areas:

- $\quad$ Physical controls to reduce access to the computer (in order to prevent manipulation).

- $\quad$ Cross-checks to make sure that all data file changes are backed up by properly authorized transactions. 
Easy to steal information

In a manual system, the loss of vast records would be immediately apparent. While in a computer-based system, vast quantities of information are stored in a small volume, therefore, can easily be copied or physically stolen. The solution to this problem is to have:

1. Good physical controls for the records.

2. Allow authorized people only to have access to the records.

Loss of information

In a manual system, the records are written in ink on paper. The only way to lose the information is to lose the physical records or to have them burnt up in a business fire (Page and Hooper, 1992). On the other hand, the information on the computer can be easily changed, leaving no trace of the earlier content. Furthermore, when a great amount of data is centralized, there is an increased risk of their loss or destruction. The solution to this problem is to provide backup copies for all data files.

\subsubsection{Problems at Output Stage}

Users trust the computer results

In a computer-based system people have the tendency to assume output information to be correct. Therefore, it is common for people to neglect checking the computer output. Effective control requires people to be at least as sceptical in a computer system as in a manual one. The solution is to provide control totals, hash control, and record controls (Wilkinson and Cerullo, 1997) to user departments to help them check the computer results. It may even be necessary to require active checks by users of the output rather than to assume that, if no one complains, it must be all right.

Different reality can be created

In some companies, the information stored in the computer does not reflect reality: yet it is taken to be real. Originally, the computer record simply reflected the operations of the firm. In extremely sophisticated applications, however, the computer record is the operations of the firm. The solution is to constantly checking information in the computer system to make sure that it is consistent with the real world.

In summary, the hierarchical relationship of the internal control problems of computerized accounting systems are shown in figure 1. Three input problems, four processing problems, four storage problems and two output problems. The issue of unauthorized access was classified as an input problem; but there are several interception risks at the processing stage and during transmission between processing and storage stages and between storage and output stages where transmitted messages may be manipulated. These problems are not examined. 
Figure 1

Internal Control Problems

\begin{tabular}{|c|c|c|c|}
\hline & $\begin{array}{r}\text { In } \\
\text { Contro } \\
\end{array}$ & & \\
\hline $\begin{array}{c}1 \\
\text { Input } \\
\text { Problems }\end{array}$ & $\begin{array}{c}2 \\
\text { Processing } \\
\text { Problems }\end{array}$ & $\begin{array}{c}3 \\
\text { Storage } \\
\text { Problems }\end{array}$ & $\begin{array}{c}4 \\
\text { Output } \\
\text { Problems }\end{array}$ \\
\hline $\begin{array}{l}\text {-Invisibility of input } \\
\text { data }\end{array}$ & $\begin{array}{l}\text {-The computer } \\
\text { equipment lacks } \\
\text { judgement }\end{array}$ & $\begin{array}{l}\text {-Invisibility of audit } \\
\text { trail }\end{array}$ & $\begin{array}{l}\text {-Users trust the } \\
\text { computer results }\end{array}$ \\
\hline $\begin{array}{l}\text {-Unauthorized } \\
\text { access }\end{array}$ & $\begin{array}{l}\text {-Centralization of } \\
\text { data and separation } \\
\text { of duties }\end{array}$ & $\begin{array}{l}\text {-Information can be } \\
\text { changed without } \\
\text { physical traces }\end{array}$ & $\begin{array}{l}\text {-Different reality } \\
\text { can be created }\end{array}$ \\
\hline $\begin{array}{l}\text {-Input of incorrect } \\
\text { data by unfamiliar } \\
\text { user. }\end{array}$ & $\begin{array}{l}\text {-Great speed of } \\
\text { computers can be } \\
\text { misused }\end{array}$ & -Data easy to steal & \\
\hline & $\begin{array}{l}\text {-Some potential for } \\
\text { errors. }\end{array}$ & -Loss of information & \\
\hline
\end{tabular}

\subsection{Controls in computer-based accounting systems}

The broad principles of internal control are generally followed for both manual and computerized accounting systems. However, techniques, procedures, and issues for internal control are different in the manual system than computer-based accounting system. In the manual system, we just have to control the attitudes of the employees and procedures of recording the transactions. But in the computer-based system, we have also to consider the software and hardware problems for internal control as well.

To achieve the objectives of internal control, management apply policies and control procedures. Moscove et al. (1997) argue that the types of controls in a computer-based accounting system can be classified into general and application controls. General controls focus on the framework within which computerized accounting systems operate. They relate to all parts of the system, while application controls apply to specific use of the system. They are concerned with preventing, detecting, and correcting errors and irregularities in transactions that are processed by computerized system where there are three major stages in executing the data processing work; accumulating the input data, processing the data, and accumulating the processed data in some form of output. They are called input controls, processing controls, and output controls respectively.

\section{Research Method}

\subsection{Population and Sample}

The list of companies for this study was taken from the Internet Web Site "Major Companies Directories" which includes about 400 companies from Bahrain. A scrutiny of this list was made and partnership type firms were excluded from the study because many of them were of very small sizes. The list then contained 246 companies and a random sample of (100) companies was selected for the present study. The sample covers three types of firms, service, merchandising, and manufacturing. In each firm the accountant was asked to fill-in a questionnaire. To complete the questionnaire, accountants were required to have an academic qualification in accounting and experi- 
ence in computer-based accounting system. This is important so that respondents can understand and judge each question. The response rate was $(62 \%)$ as 62 questionnaires were returned.

\subsection{The Questionnaire}

A questionnaire was developed to elicit the perceptions of Bahraini accountants on the level of internal control problems confronting them when using computerized accounting systems. Due to somewhat large sample size (100), a questionnaire was considered to be an appropriate data collection method. The questionnaire was pilottested in four selected firms before sending it to the entire sample. Interviews were conducted with the accountants in each of the four firms. Comments were very helpful in developing the final draft of the questionnaire.

The questionnaire consists of three sections. Section I includes background information about companies (e.g. type of business, the size of the firm, the date computer-based accounting system was introduced, the degree of reliance on computers in their accounting systems, and the academic qualification and the experience of respondents). Section II collects data on the internal control concerns in computer-based systems. The last section elicits information about proposed solutions to overcome the internal control problems associated with computerized accounting systems.

\subsection{The Procedure}

The questionnaire was delivered by the authors, during the first semester 1999/2000, to accountants in each of the (100) firms. They were informed that it should be completed by them or by someone who is familiar with computer-based accounting systems. The accountants were required to have an academic qualification and experience in computer-based accounting system. The questionnaire may also be completed by someone who is familiar with computer-based accounting system instead of the accountant. This procedure is likely to provide two assurances that a competent person would complete the questionnaire. First, the accountant has to identify that a competent person would complete the questionnaire. As a person familiar with the system-but not necessarily an expert. Second, the person responding has to indicate his/her usage experience. Finally, descriptive statistics such as frequency distributions, percentage distribution of responses, means, standard deviation, and ANOVA were used to analyse the data.

\section{Results}

\subsection{Characteristics of firms and respondents}

\subsubsection{The size of the firm and respondents' academic qualifications}

The responding companies covered in this study were three major types of firms, namely: $14(23 \%)$ manufacturing, 12 (19\%) merchandising, and 36 (58\%) service firms. Number of employees was used a measure of company size. Respondents were asked to indicate the total number of employees working in their firms. Table (1) shows that the largest group employs (more than 500) employees (40.3\%). About (42\%) employ less than 200 and about 18\% employ between 200 and 500. Overall, the responding firms cover a range of different sizes, large, medium and small, i.e., the size measured by the number of employees varied considerably among the responding firms.

Table 1

Size of firm measured by number of employees ( $\mathrm{N}=$ responding firms)

\begin{tabular}{|l|r|r|}
\hline \multicolumn{1}{|c|}{ Number of employees } & $\underline{\mathrm{N}}$ & $\underline{\%}$ \\
\hline Less than 100 & 16 & 25.8 \\
\hline $100-200$ & 10 & 16.1 \\
\hline $201-300$ & 6 & 9.7 \\
\hline $301-500$ & 5 & 8.1 \\
\hline More than 500 & $\underline{25}$ & $\underline{40.3}$ \\
\hline Totals & $\underline{62}$ & $\underline{100.0}$ \\
\hline
\end{tabular}


Respondents were also asked about their academic qualification. Table (2) shows that most of the responding accountants (38.4\%) have B.Sc. or B.Com., (13\%) Masters, (1.6\%) Ph.D., (17.7 \%) CPA, CA, ACCA or equivalent, such as CIMA, and the remaining (11.3\%) have other qualifications such as Associate Diploma (two years study at the University of Bahrain), or hold both academic and professional qualification.

Table 2

The academic qualification of respondents

\begin{tabular}{|l|r|r|}
\multicolumn{1}{l}{} & N & \% \\
\hline B.Sc. & 35 & 56.5 \\
\hline Masters & 8 & 12.9 \\
\hline Ph.D. & 1 & 1.6 \\
\hline CPA, CA, ACCA or equivalent & 11 & 17.7 \\
\hline Others (e.g. Associate Diploma) & $\underline{7}$ & $\underline{11.3}$ \\
\hline Totals & $\underline{62}$ & $\underline{100.0}$ \\
\hline
\end{tabular}

\subsubsection{Experience in computer-based accounting systems}

Respondents were asked to indicate for how long their companies have been using computer-based accounting. Table (3) shows that most of the responding companies $(58 \%)$ introduced computers for more than 10 years $(16 \%)$ between 6 - 10 years, $(21 . \%)$ between 2 - 5 years, and (5\%) less than 2 years. This indicates that most companies have some experience in using computer-based accounting systems.

Respondents were also asked about their experience in computerized accounting. Table (3) shows that some respondents (19\%) have experience of less than 2 years, (19\%) between 2 - 5 years, (32\%) between 6 - 10 years, and (29\%) of more than 10 years. As far as companies' reliance on computers in their accounting systems is concerned, the study shows that most firms rely heavily on computers. About $23 \%$ of total firms use computers between $61 \%$ $80 \%$ of their transactions and about $19 \%$ are moderate users and the remaining $4.8 \%$ are light users. The results show that, by and large, all firms are dependent on computers to some extent. Although the majority of respondents indicated familiarity with computer-based systems, it is surprising that nearly $30 \%$ of the respondents had less than 5 years' familiarity with computer-based systems. Probably more respondents than those with less than 5 years' experience would be familiar with internal controls embedded in those computer-based systems. Perceptions of the level/importance of internal control problems encountered in the use of computerized accounting systems would include all the situational factors affecting Bahraini accountants' feelings about computerized accounting systems, such as their technical competence, organizational competence with electronic data processing (EDP) unit, communication with the EDP staff, attitudes of the EDP staff and organizational position of the EDP staff. All of which are predictors of problems of Bahraini accountants on the internal control problems encountered in their use of computerized accounting systems. 
Table 3

Experience in computer-based accounting systems

\begin{tabular}{|c|c|c|}
\hline & 1.Number of years computer-based accounting was introduced & $\underline{\%}$ \\
\hline Less than 2 years ago & 3 & 4.8 \\
\hline $2-5$ years ago & 13 & 21.0 \\
\hline $6-10$ years ago & 10 & 16.1 \\
\hline More than 10 years ago & $\underline{36}$ & $\underline{58.1}$ \\
\hline Totals & $\underline{62}$ & $\overline{100.0}$ \\
\hline \multicolumn{3}{|c|}{ 2. Respondents' experience in computer-based accounting systems } \\
\hline Less than 2 years & 12 & 19.4 \\
\hline $2-5$ years & 12 & 19.4 \\
\hline $6-10$ years & 20 & 32.2 \\
\hline More than 10 years & $\underline{18}$ & 29.0 \\
\hline Totals & $\underline{\underline{62}}$ & $\underline{\underline{100.0}}$ \\
\hline \multicolumn{3}{|c|}{ 3. Degree of reliance on computer-based accounting systems } \\
\hline Less than $40 \%$ & 3 & 4.8 \\
\hline $40 \%-60 \%$ & 12 & 19.4 \\
\hline $61 \%-80 \%$ & 14 & 22.6 \\
\hline More than $80 \%$ & $\underline{33}$ & $\underline{53.2}$ \\
\hline Totals & $\underline{62}$ & $\underline{100.0}$ \\
\hline
\end{tabular}

\subsection{Internal Control Problems Specific to Computerised Accounting Systems}

Respondents were asked to indicate, on a five-point Likert-type scale ranging between 1 (not likely to occur) and 5 (most likely), to indicate the internal control problems associated with their computerized accounting systems. Survey responses are presented in Table 4. They are reported as a percentage of the total responses on each problem.

The table shows that all problems achieved above average scores ( 3 or more). The overall score is just above (3.31). Some problems received high rating (4 or more). This indicates that respondents perceive all problems as most likely to occur. The problem, "duties are concentrated within the computer" received slightly less than average score; it received the lowest score (2.97). One respondent indicated that the problem "information can be changed without physical traces" is not likely to occur because systems now log all changes. One firm stated that they do not face the problem "accounting records and the audit trail are invisible".

Respondents were also asked to indicate how often they check the computer output. About $9 \%$ said rarely; $13.6 \%$ said sometimes and about $77 \%$ said often and always. Respondents were asked to add any other problems they felt important. None of them added any problem other than those stated in the questionnaire.

Finally, it was expected that the problems will not differ among firms according to the nature of their business operations (i.e., manufacturing, merchandising, or service firms).

Therefore, ANOVA was used to test this assumption. Table 4 shows that there were significant differences at the .05 level with regard to the following problems:

- $\quad$ Duties are concentrated within the computer $(\mathrm{F}=6.74)$.

- $\quad$ Concentrated information is easy to steal $(\mathrm{F}=4.13)$.

- $\quad$ Electronic information is easy to lose $(\mathrm{F}=4.19)$.

- Information stored in the computer may not reflect reality $(\mathrm{F}=3.80)$.

The above four problems, which are considered significant, indicate that problems faced by companies may be influenced by the nature of business operations. It is obvious that differences in the problems may arise because when independent checks are done in practice, the matter and the procedure followed for checks differ between the 
firms because of the factors which affect the level of complexity in operations (e.g., size, the way the system is implemented, and the competency and training of their employees).

Table 4 - Internal control problems associated with the use of computers $(N=62)$

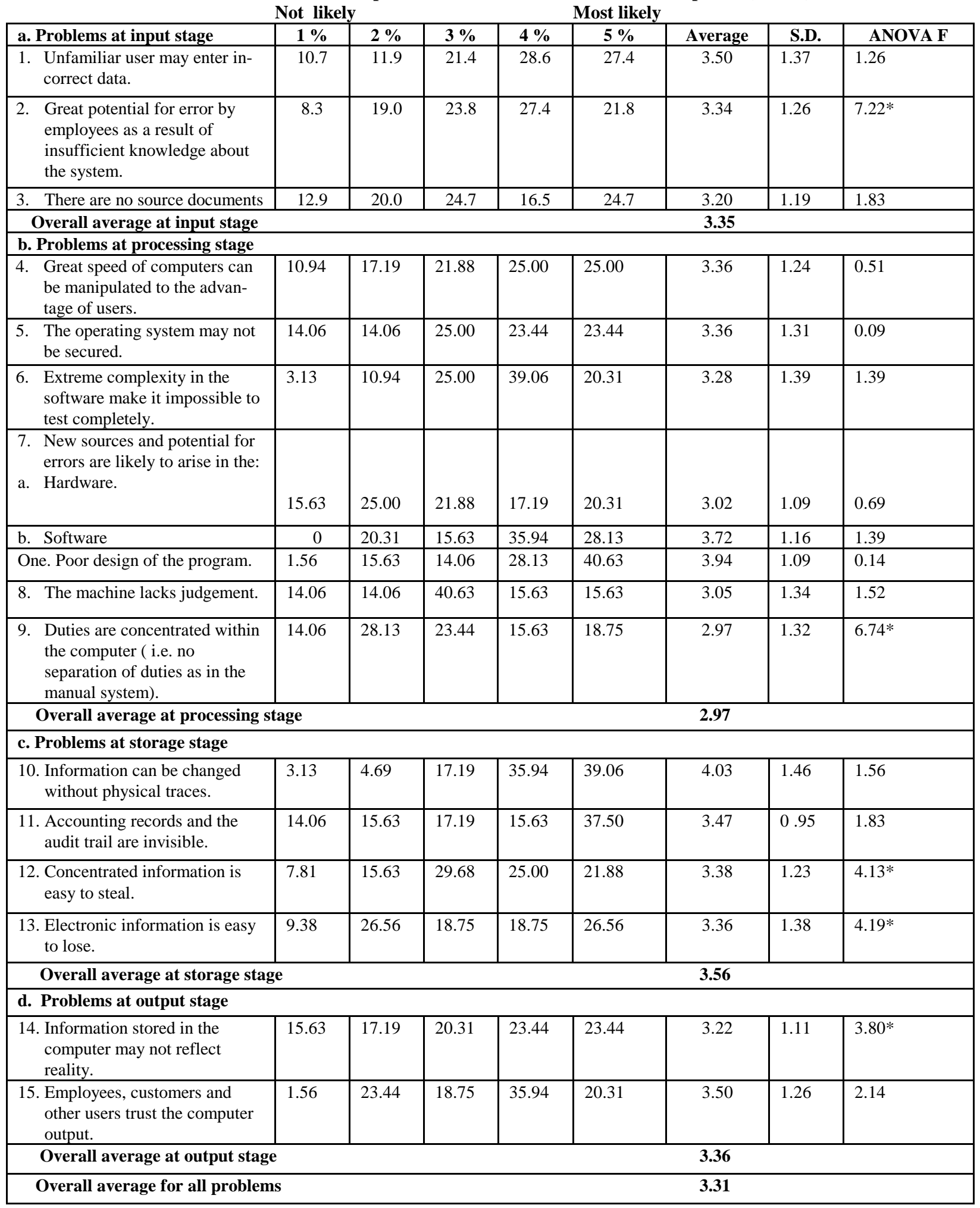

* Significant at the 05 level. 


\subsection{Solutions to overcome the problems}

The proposed solutions mentioned in the literature were included in the questionnaire and respondents were asked to check the importance attached to each solution. Table 5 shows that the most important solution is to "ensure that only authorised people have access to terminals, i.e., access control" and that "the computer programs must contain extensive edit checks to detect and help correct errors". "Proper system design", "extensive testing of programs before use", "physical controls" and "use of backup copies" were also considered important. Almost all respondents perceived the solutions as most likely to overcome the problems.

When respondents were asked how often they take a backup copy, the replies were: $4.5 \%$ use on-line backup; $92 \%$ on a daily basis, and $3.5 \%$ on a weekly basis. This indicates that respondents are aware of the importance of backup copies to retrieve the data in case of loss or system failure. Some respondents (45.5\%) indicated that they keep backup files inside the organisation, and the majority (54.5\%) keep them outside the firm. Only one solution "make independent checks with the real world" is significant at the .05 level. This may indicate that solutions may not be influenced by the nature of business operations. It is obvious that differences in the solutions may arise because of the factors, which affect the level of complexity in operations (e.g., size, the way the system is implemented, and the competency and training of their employees).

Table 5

Proposed Solutions to Overcome the Problems ( $=62)$

\begin{tabular}{|c|c|c|c|c|c|c|c|c|}
\hline A. Solutions at input stage & $\begin{array}{l}1 \\
\%\end{array}$ & $\begin{array}{l}2 \\
\%\end{array}$ & $\begin{array}{l}3 \\
\%\end{array}$ & $\begin{array}{l}4 \\
\%\end{array}$ & $\begin{array}{l}5 \\
\%\end{array}$ & Average & S.D. & $\begin{array}{c}\text { ANOVA } \\
\text { F }\end{array}$ \\
\hline $\begin{array}{l}\text { 1. Ensure that only authorized } \\
\text { people have access to } \\
\text { computers. }\end{array}$ & 4.69 & 3.13 & 7.81 & 25.00 & 59.38 & 4.31 & 1.23 & 0.14 \\
\hline $\begin{array}{l}\text { 2. The computer programs } \\
\text { must contain extensive edit } \\
\text { checks to detect and help } \\
\text { correct errors. }\end{array}$ & 0 & 9.38 & 4.69 & 39.06 & 46.88 & 4.23 & 1.09 & 1.78 \\
\hline $\begin{array}{l}\text { 3. Physically control access to } \\
\text { terminals. }\end{array}$ & 4.69 & 10.94 & 15.63 & 23.44 & 45.31 & 3.94 & 0.94 & 0.08 \\
\hline \multicolumn{4}{|l|}{ Average } & \multicolumn{5}{|c|}{4.16} \\
\hline \multicolumn{9}{|l|}{ B. Solutions at processing stage } \\
\hline 4. Proper system design & 0 & 10.94 & 9.39 & 35.94 & 43.75 & 4.13 & 1.23 & 0.28 \\
\hline $\begin{array}{ll}5 . & \text { Effective testing of } \\
\text { programs prior to their use. }\end{array}$ & 3.13 & 10.94 & 9.38 & 18.75 & 57.81 & 4.10 & 1.13 & 0.53 \\
\hline $\begin{array}{l}\text { 6. Segregate duties within data } \\
\text { processing. }\end{array}$ & 4.69 & 4.69 & 9.38 & 42.19 & 39.06 & 4.06 & 1.19 & 1.33 \\
\hline $\begin{array}{l}\text { 7. Use physical controls and } \\
\text { proper authorization. }\end{array}$ & 6.25 & 7.81 & 14.06 & 25.00 & 46.88 & 3.98 & 0.99 & 0.44 \\
\hline $\begin{array}{l}\text { 8. Computer systems can have } \\
\text { built into judgement } \\
\text { programs. }\end{array}$ & 3.13 & 10.94 & 23.44 & 29.69 & 32.81 & 3.78 & 1.23 & 0.32 \\
\hline \multicolumn{4}{|l|}{ Average } & \multicolumn{5}{|c|}{4.00} \\
\hline \multicolumn{9}{|l|}{ C. Solutions at Storage Stage } \\
\hline 9. Use backup copies. & 1.56 & 6.25 & 9.38 & 14.06 & 68.75 & 4.42 & 1.10 & 0.67 \\
\hline $\begin{array}{l}\text { 10. Only authorized people } \\
\text { should have access to the } \\
\text { records. }\end{array}$ & 4.69 & 6.25 & 4.69 & 28.13 & 56.25 & 4.25 & 1.23 & 2.00 \\
\hline $\begin{array}{l}\text { 11. Use physical control and } \\
\text { cross-checks. }\end{array}$ & 3.13 & 7.81 & 17.19 & 31.25 & 40.63 & 3.98 & 1.02 & 0.06 \\
\hline \multicolumn{4}{|l|}{ Average } & \multicolumn{5}{|c|}{4.22} \\
\hline
\end{tabular}




\begin{tabular}{|c|c|c|c|c|c|c|c|c|}
\hline \multicolumn{9}{|l|}{ D. Solutions at output Stage } \\
\hline $\begin{array}{l}\text { 12. Use control totals to check } \\
\text { computer results. }\end{array}$ & 1.56 & 10.94 & 18.75 & 31.25 & 37.50 & 3.92 & 1.05 & 0.44 \\
\hline $\begin{array}{l}\text { 13. Make independent checks } \\
\text { with "real world". }\end{array}$ & 4.69 & 9.38 & 18.75 & 40.63 & 26.56 & 3.75 & 1.14 & $3.41 *$ \\
\hline \multicolumn{4}{|l|}{ Average } & \multicolumn{5}{|c|}{3.84} \\
\hline \multicolumn{4}{|c|}{ Overall average for all solutions } & \multicolumn{5}{|c|}{4.06} \\
\hline
\end{tabular}

* Significant at the .05 level.

Table 6 shows the overall average of the problems and solutions at each stage (i.e., input, processing, storage and output). The results indicate that problems at the storage stage (ranked 1) are the most complex, followed by the input stage (ranked 2), processing stage (ranked 3) and finally output stage (ranked 4). The same result also applies to solutions, which indicate that problems at the storage stage received the highest average. This is consistent with the problems. The reason for this may be that, as the number of transactions increase, problems of storage may become complex because of increase in input data, programs and output results. Also information can be stolen, copied, lost with no physical traces. Finally, since computer technology changes rapidly, firms also keep on up-dating their systems to overcome these problems.

Table 6

Overall average of problems and solutions for each stage

\begin{tabular}{|l|c|c|c|}
\hline a. Problems & No of items & Average & Rank \\
\hline 1. Input & 3 & 3.49 & 2 \\
\hline 2. Processing & 8 & 3.35 & 3 \\
\hline 3. Storage & 4 & 3.54 & 1 \\
\hline 4. Output & 2 & 3.26 & 4 \\
\hline b. Solution & & & \\
\hline 1. Input & 3 & 4.12 & 2 \\
\hline 2. Processing & 5 & 3.98 & 3 \\
\hline 3. Storage & 2 & 4.32 & 1 \\
\hline 4. Output & 2 & 3.84 & 4 \\
\hline
\end{tabular}




\section{Summary and Conclusion}

Computer-based accounting systems may have some weaknesses in internal control. Problems with data input stem from lack of documentation, susceptibility to tampering, and human error. Processing problems result from the machine's inability to reason; duties are concentrated within the computer; faulty hardware; software or poor system design; the impossibility of completely testing complex software; and great speed of computers can be manipulated to the advantage of users. Storage problems arise because computerized information can easily be changed, stolen, copied or lost with no physical traces. Output may not be controlled properly because people tend not to question it.

The elements of accounting control in a computer environment are the same as in a manual environment, but implementation is different. Employees should operate the computer properly. System analysts and programmers must not work with operators and clerks. Access to terminals should be restricted to those responsible for authorizing and initiating transactions, terminal dialogue should check for error, the system should log and detect errors in messages, and new systems and programs should be properly authorized. In addition, procedures should be in place to provide hardware and software backups in the event of system failure. The system must back up information and test the backups periodically; it must have adequate documentation to explain systems, programmes, and operator instructions; and it must have standards for documentation, security measures, authorization of requests for data processing and computer operation and file maintenance. Data must be protected and equipment protected and maintained. The findings indicate that all these problems have been taken care of and no authentic program is launched without extensive testing. The advances in information technology made it possible to overcome these problems.

One limitation of the study is the lack of sufficient prior research. Therefore, Page and Hooper (1992) was heavily referenced to identify the problems and their proposed solutions. In addition, the underlying study relied upon perceptual measures which served as a surrogate for each Bahraini accountant's "truthful" beliefs about the internal control problems of their computerized accounting systems. As a result, measurement bias in terms of the perception ratings used in this study may also exist.

\section{Suggestions for Future Research}

For further research, accountant's perceptions regarding the internal control problems of a computer system using communication links to remote locations could be examined. A particular concern must be "hackers" data communication experts who delight in unauthorised break-ins into computers. In this case, on-line transaction processing becomes dependent on the phone system. This allows access by outside hackers and errors can be introduced during communications. Additionally, there has been rapid expansion of E-Commerce activities in which accountants are expected to play a significant role in respect of controls. The future research may examine the types of problems being faced by E-Commerce firms and what kind of role the accountants are playing.

\section{References}

1. American Institute of Certified Public Accountant. Codification of Auditing Standards and Procedures, Statement on Auditing Standards No. 1 (AU 320.08), New York: AICPA, 1972.

2. Arens, A..and James, Loebbecke. Auditing: An Integrated Approach, $7^{\text {th }}$ edition, Prentice-Hall, International, New Jersey. 1997.

3. Committee of Sponsoring Organisations of the Treadway Commission. Internal Control Integrated Framework (COSO Report), USA., 1992.

4. Drew, J. Accounting for Internal Control in the Age of the Small Business Computer, Accountancy Age, April, pp.26-27, 1980.

5. Hall, James. Accounting Information Systems, $2^{\text {nd }}$ edition, South Western College Publishing, Cincinati, Ohoi, 1995.

6. Hearing, Sylvia. Computerized Accounting - An Integrated Skills Approach, $2^{\text {nd }}$ ed., New Jersey, Prentice Hall, Inc., 1994.

7. Holm, Cl. and Peter, B, Laursen. "Is COSO enough from a Corporate Governance Perspective?" A paper presented at the Twenty fifth European Accounting Association Annual Congress, 25-27 April, Copenhagen, Denmark, 2002. 
8. $\quad$ Larson, K. and Paul, Miller. Fundamental Accounting Principles, $13^{\text {th }}$ edition, Irwin, 1997.

9. Leitch, R. A. and K, R. Davis. Accounting Information Systems-Theory and Practice, $2^{\text {nd }}$ edition, New Jersey, Prentice-Hall, Inc., 1992.

10. Monroe, G. S. Juliana. K. L. Ng. and David, Woodliff. "The Importance of Inherent Risk Factors, Auditors' Perceptions", A paper presented at the $16^{\text {th }}$ Annual Congress of the European Accounting Association, Turku-Finland, 16-18 April., 1993.

11. Moscove, Stephen. Mark, G. Simkin. and Nancy, A. Bagranoff. Core Concepts of Accounting Information Systems, Fifth Edition, John Wiley \& Son Inc., 1997.

12. Page, John. and Paul, Hooper. Accounting Information Systems, 4th edition, New Jersey, Prentice -Hall, Inc., 1992.

13. Pesqueux, Yvon. "Control and New Technologies: Delegation and Automation", a paper presented at the $16^{\text {th }}$ Annual Congress of the European Accounting Association, Turku-Finland, April, 1993.

14. Romeny, M. B., P. J. Steinbart. and B. Cushung. Accounting Information System, $7^{\text {th }}$ edition, Addison Wesley Publishing Company, 1997.

15. Summers, E. L. Accounting Information Systems, $2^{\text {nd }}$ edition, Houghton Mifflin Company, 1991.

16. Walsh, J. Anthony. "Empirical Evidence on Internal Control in Minicomputer Based Accounting Information Systems", Accounting and Business Research, Summer, pp. 227-233, 1986.

17. Warren, A. “Controls and the Minicomputer: An Auditor's View”, Accountancy, December, pp.119-120, 1981.

18. Wilkinson, J. W. and Cerullo, M. J. Accounting Information Systems, $3^{\text {rd }}$ ed., NY: John Wiley \& Sons, Inc., 1997. 